\title{
Outcome of aortic valve repair in children with congenital aortic valve insufficiency
}

Nahidh Hasaniya, MD, $\mathrm{PhD}^{\mathrm{a}}$

Steven R. Gundry, MD ${ }^{\mathrm{a}}$

Anees J. Razzouk, MDa

Neda Mulla, MD ${ }^{\mathrm{b}}$

Leonard L. Bailey, MD

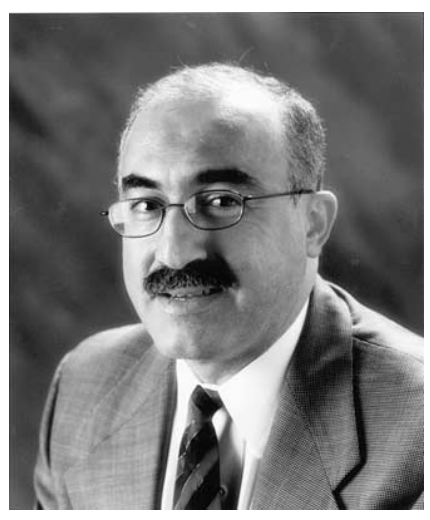

Dr Hasaniya
From the Divisions of Cardiothoracic Surgery $^{\mathrm{a}}$ and Pediatric Cardiology, ${ }^{\mathrm{b}}$ Loma Linda University Medical Center, Loma Linda, Calif.

Read at the Eighty-second Annual Meeting of The American Association for Thoracic Surgery, Washington, DC, May 5-8, 2002.

Received for publication June 5, 2002; revisions requested Oct 1, 2003; revisions received Oct 10, 2003; accepted for publication Oct 17, 2003.

Address for reprints: Nahidh W. Hasaniya, $\mathrm{MD}, \mathrm{PhD}$, Loma Linda University Medical Center, Division of Cardiothoracic Surgery, 11175 Campus Street, Suite 21121, Loma Linda, CA 92354 (E-mail: nahidh@ pol.net).

J Thorac Cardiovasc Surg 2004;127:970-4

0022-5223/\$30.00

Copyright (C) 2004 by The American Association for Thoracic Surgery

doi:10.1016/j.jtcvs.2003.10.023
Objective: Surgical aortic valvotomy has a long history of providing excellent palliation for aortic stenosis in infancy and childhood. The fate of aortic valve repairs for dominant aortic regurgitation in this same age group is considerably less clear.

Methods: From 1990 to 2000, a total of 21 patients underwent aortic valve repair for aortic regurgitation at our institution. Seventeen patients were younger than 17 years at the time of repair (3-17 years, mean $8.1 \pm 3.7$ years). Of these 17 children, 6 $(35 \%)$ had bicuspid valves and $11(65 \%)$ had tricuspid valves. Type of repair varied with valve type, but repair generally consisted of commissure resuspension, partial commissure closure, triangular resection of redundant leaflets, or some combination.

Results: There were no deaths. Follow-up ranged from 1 to 11 years (mean $5.3 \pm$ 2.4 years). At present 3 of 17 (17.6\%) have mild aortic regurgitation according to echocardiography and $6(35.2 \%)$ have moderate aortic regurgitation. In 8 of 17 cases $(47.1 \%)$ the repair clearly failed, requiring reoperation from 0.5 to 73 months after the original operation (mean 18.9 months). Reoperation consisted of 6 Ross procedures and 2 mechanical aortic valve replacements. There were no deaths at the secondary operation.

Conclusion: Aortic valve repair in children with a dominant feature of aortic insufficiency tended to fail progressively and at a high rate. Leaflet thickening was associated with higher risk of repair failure in this series. The threshold for aortic valve replacement should remain low.

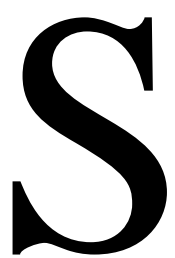

urgical aortic valvotomy has a long history of providing durable palliation for aortic stenosis in infancy and childhood. Aortic valve repair for dominant valve regurgitation has been less reliable, however, and, despite its attractiveness, its efficacy remains debatable. ${ }^{1,2}$ Longer follow-up of patients with repaired aortic valves suggests that valvuloplastic techniques are not without limitations, particularly among patients with severely diseased and deformed aortic valves. ${ }^{3}$ Mechanical valves are not an ideal semilunar valve substitute in young children because of size limitation and the frequent requirement for left ventricular outflow augmentation with their use. They also require lifetime anticoagulation. Xenografts and homografts are considered poor alternatives for this age group of patients because of rapid degeneration and calcification. The Ross procedure has produced excellent results in children because of the growth potential of the pulmonary autograft and the avoidance of anticoagulation therapy. However, pulmonary valve replacement with an allograft conduit leaves much to be desired, and neoaortic valve dilatation and regurgitation can become an important issue when the Ross operation is done 


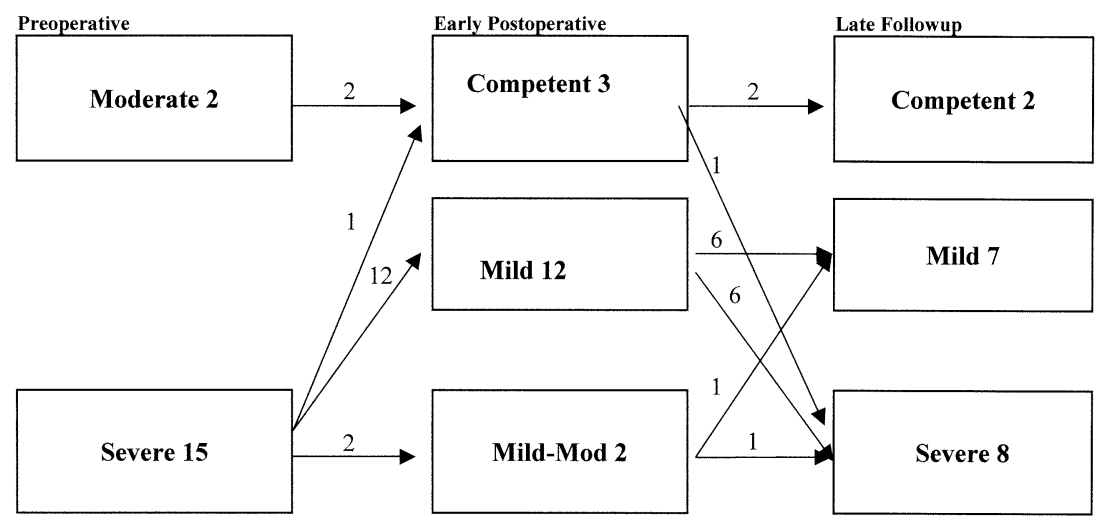

Figure 1. Scheme showing postoperative change in degree of aortic valve regurgitation in 17 children after repair.

for pure aortic regurgitation in small children. ${ }^{4}$ Thus there remains strong incentive to develop reliable techniques of aortic valve repair.

In this study we present our experience with aortic valve repair in pediatric patients with predominant aortic insufficiency. We analyzed the efficacy of the various valvuloplastic techniques used among these pediatric patients.

\section{Patients and Methods}

The Loma Linda University Medical Center and Children's Hospital combined aortic valve procedure database between January 1990 and March 2001 was examined, and all cases of children who required operation for aortic valve insufficiency were evaluated. Among the 854 aortic valve operations accomplished, a total of 21 patients $(2.4 \%)$ had valve repair for moderate to severe aortic insufficiency. Seventeen of these patients were younger than 17 years at the time of repair and are the subjects of this outcome analysis. All patients were evaluated with 2-dimensional echocardiograms and Doppler studies before the operation. Of the 17 pediatric patients, 10 were male $(58 \%)$ and 7 were female $(42 \%)$. Age of the patients at the time of aortic valvuloplasty ranged between 3 and 17 years, with a mean of $8.1 \pm 3.7$ years. Preoperative aortic regurgitation was moderate in 2 patients and severe in 15 patients. Indication for surgery was the presence of moderate to severe aortic regurgitation resulting in progressive increase in left ventricular dimensions $(\mathrm{n}=17)$. Ten patients had isolated aortic insufficiency, 3 had an associated ventricular septal defect, 1 had concomitant mitral regurgitation, and 3 had echocardiographic evidence of aortic insufficiency associated with some degree of aortic valve stenosis. Aortic regurgitation was graded echocardiographically as mild when the regurgitation jet reached $25 \%$ of the distance from the aortic valve and the left ventricular apex, moderate when the jet reached $50 \%$ of this distance, and severe when the jet reached more than $50 \%$ of this distance.

\section{Structure of the Aortic Valve at Operation}

The valve was bicuspid in 6 patients $(35 \%)$ and tricuspid in 11 $(65 \%)$. The valve leaflets showed various degrees of prolapse, tethering, laxity, and leaflet thickening with rolled free margins. Three patients with clearly abnormal valves had evidence of leaflet disruption or perforation. Lack of cusp coaptation appeared to be the main contributing factor to aortic regurgitation in most cases. All patients had congenital heart disease. No patient had a history of rheumatic fever or genetic connective tissue disease such as Marfan disease. None of these patients had annular or annuloaortic ectasia. There were no traumatic disruptions or iatrogenic perforations among the pediatric patients in this series.

\section{Surgical Techniques}

Operations were performed with standard cardiopulmonary bypass and systemic hypothermia of $20^{\circ} \mathrm{C}$ to $28^{\circ} \mathrm{C}$. Not infrequently, a left ventricular vent was placed through the right superior pulmonary vein. The aorta was clamped, and an oblique aortotomy was made and extended into the region of the noncoronary aortic valve sinus. The aortic valve was examined carefully to assess the possibility of repair. Myocardial preservation was ensured by use of topical hypothermia, usually combined either with antegrade cold cardioplegia solution delivered directly into both coronary ostia or with retrograde cold blood cardioplegia. The average aortic crossclamp time for pure aortic valve repair was $51 \pm 21$ minutes, and the cardiopulmonary bypass time averaged $86 \pm 27$ minutes.

\section{Valve Reconstruction}

The type of repair to achieve competence varied with valve pathology but generally consisted of the following: (1) leaflet plication with commissure resuspension; (2) leaflet thinning, release of thickened leaflets, or partial commissure closure; (3) triangular resection and repair of redundant leaflets; and (4) repair of torn or perforated leaflets. The quality of repair was assessed by transesophageal echocardiography after discontinuation of cardiopulmonary bypass. All these patients had redundancy of leaflet tissue. None of them had major commissural fusion. Accordingly, commissurotomy and cusp augmentation were not used in this group of patients. Reduction valvuloplasty techniques were deemed sufficient.

\section{Follow-up}

Follow-up ranged from 1 to 11 years, with a mean of $5.3 \pm 2.4$ years. Two-dimensional echocardiographic examinations with Doppler studies were performed before discharge and every 6 
TABLE 1. Aortic valve repair failures

\begin{tabular}{|c|c|c|c|c|}
\hline Age (y) & Valve pathology & Surgical procedure & Late procedure & Time to failure (mo) \\
\hline 10 & $\mathrm{TL}$, cusp perforation & $\mathrm{LP}, \mathrm{CP}$ & Replacement & 4 \\
\hline 9 & $\mathrm{TL}$, prolapse & LP & Replacement & 73 \\
\hline 6 & Tear, prolapse & Tear repair & Ross & 0.5 \\
\hline 4 & Prolapse, TL & Midleaflet excision, CP & Ross & 56 \\
\hline 13 & Tear, prolapse & Cusp repair & Ross & 3 \\
\hline 9 & Prolapse, TL & $\mathrm{CP}$ & Ross & 30 \\
\hline 12 & Prolapse, TL & $\mathrm{CP}$, LP, leaflet shaving & Ross & 8 \\
\hline 7 & Prolapse, TL & $C P, L P$ & Ross & 3 \\
\hline
\end{tabular}

$T L$, Thickened leaflet(s); $L P$, leaflet plication; $C P$, commissure plication.

TABLE 2. Leaflet structural defects in the failed and successful repair groups

\begin{tabular}{lcccc}
\hline & Thickening & $\begin{array}{c}\text { Rolled } \\
\text { edge }\end{array}$ & $\begin{array}{c}\text { Pliable, } \\
\text { soft }\end{array}$ & Tethering \\
\hline Successful $(\mathrm{n}=9)$ & $1 / 9$ & $2 / 9$ & $6 / 9$ & $2 / 9$ \\
Failed $(\mathrm{n}=8)$ & $5 / 8$ & $2 / 8$ & $3 / 8$ & $2 / 8$ \\
$P$ value & .04 & .51 & .21 & .50 \\
\hline
\end{tabular}

NS, Not statistically significant.

months after the operation. The degree of aortic insufficiency and left ventricular remodeling or dilatation was assessed. All patients were examined regularly for signs or symptoms of heart failure. Data are expressed as mean \pm SD and analyzed by means of Student $t$ test and Pearson $\chi^{2}$ tables.

\section{Results}

There were no operative deaths. No significant complications occurred among this group of patients. The degree of aortic insufficiency decreased in all patients immediately after surgery, as shown in Figure 1. The aortic valve was initially competent after repair in 3 patients (18\%), mildly incompetent in 12 patients $(71 \%)$, and moderately incompetent in 2 patients $(11 \%)$. Left ventricular dimension decreased significantly among patients whose repair remained stable after aortic valve repair $(P<.05)$. The repair failed in 8 of 17 patients $(47 \%)$, however, leading to reoperation (Table 1). The failures occurred between 1 and 73 months after the initial operation (mean $28.3 \pm 28.6$ months) and were largely characterized by progressive increase in degree of aortic insufficiency with concomitant increase in left ventricular dimensions. Six of the patients with failed aortic valve repairs were treated with the Ross pulmonary valve autograft procedure. Mechanical valves were used for valve replacement in the other 2 cases. There were no deaths at the follow-up operation.

Three patients had some form of valve leaflet disruption. Two of these had torn noncoronary cusps. The noncoronary cusps in both patients had severe prolapse, small congenital fenestrations, leaflet thickening, and rolled edge. Additional prolapse of the right coronary cusp was present in one of the patients. Another patient had leaflet perforation (or a large congenital vacule or fenestration) of the right coronary cusp associated with severe prolapse and thickening. Repair involved primary suturing $(\mathrm{n}=1)$ patching with autologous pericardium $(n=2)$, leaflet thinning, triangular resection, and commissuroplasty. All 3 had early failure (Table 1). One patient had partial breakdown of the repaired leaflet tear, and the other 2 had failure as a result of progression of intrinsic leaflet abnormalities. Only 1 of 9 successful repairs had significant valve leaflet thickening, compared with 5 of 8 failures $(P=.04)$. Although 6 of the 9 successful aortic valve repairs had soft, elongated, and prolapsed leaflets, compared with 3 of 8 failures, this difference did not reach statistical significance. Apart from leaflet thickening, no structural anomaly reached statistical significance between the 2 groups (Table 2). Among the different structural defects, leaflet thickening alone was predictive of aortic valve repair failure, although valve repairs for leaflet disruption or perforation also failed during postoperative surveillance. Initial adequacy of repair, as determined by intraoperative transesophageal echocardiography, failed to predict durability of the repair.

\section{Discussion}

Repair of congenital aortic valve disease is at best an evolving art, the science behind which is complex and incomplete. The valve annulus, sinuses of Valsalva, leaflets, commissures, and sinotubular region create the ideal geometry to achieve aortic valve competence. Aortic valve repair may involve surgical adjustment to any one or several of these geometric features. ${ }^{5,6}$ Congenital aortic valve regurgitation in early life may be particularly difficult to repair, because several of the important geometric features may be developmentally abnormal, such as bicuspid or dysplastic leaflets, subvalve tethering by membranous attachments, annular ectasia, and poorly developed sinuses. Even if the dominant physiologic feature is aortic regurgitation, there is frequently an element of real or potential stenosis, which further complicates repair of the regurgitation. In addition, prolapsed aortic valve leaflets relating to subarterial and perimembranous ventricular septal defects represent cases 
in which the stretched and elongated cusp will never again be entirely normal, despite attempts to shorten the free edge. Each of these issues represents a significant challenge to durable surgical repair. As if these challenges were not enough, the usual approach to aortic valve surgery largely precludes a suitable means of immediate in situ testing. Thus aortic valve repair becomes an exercise in trial and error, with transesophageal echocardiography the mainstay of assessment. In addition, because it is nearly impossible to correct each abnormal feature playing a role in valve regurgitation, even a repair with a splendid initial outcome, as viewed by surface or transesophageal echocardiography, may fail miserably with time. Several patients in this small series are examples of progressive late failure of what initially appeared to be a suitable repair. Alternatives to aortic valve repair among infants and children, such as the pulmonary valve transfer or use of a mechanical prosthesis, carry their own array of immediate and long-term hazards, issues that create strong incentives to repair the valve.

Several techniques of aortic valve repair have been described in the literature and have produced variable results. ${ }^{4-11}$ Techniques of valve repair used in this study are identical to those that have been clearly depicted in the study by Haydar and colleagues. ${ }^{12}$ A recent study describes more than 3 years of favorable outcomes with semilunar leaflet augmentation with autologous pericardium in severe rheumatic aortic insufficiency. ${ }^{7}$ Autologous pericardium was used to complete valve repair in only 2 patients in our series, and both repairs failed. Some investigators believe that the most important factor determining the success of valve repair remains the initial quality of the aortic valve leaflets. Our results support this point of view. There must be enough leaflet tissue of satisfactory quality to allow restoration of normal coaptation. Aortic valve repair with cusp extension with autologous or bovine pericardium has been described, with what seems excellent initial success. ${ }^{8-10}$ Long-term results, however, are not yet available. In an editorial response by Aitizaz-Uddin and coworkers, ${ }^{11}$ however, long-term results in 20 patients treated by cusp augmentation with bovine pericardium were not encouraging. This technique was not used among patients in our series.

Our experience, and that of others, suggests that multiple techniques are required in tailoring the repair of aortic valves. No single technique can reliably achieve a suitable result. ${ }^{12}$ Although satisfactory results with aortic valve repair by variable techniques have been reported, $47 \%$ of the pediatric valve repairs in this series failed, either early or with time. Thickened, disrupted, or perforated aortic valve leaflets, which imply a higher degree of structural damage, appear to increase the chance of repair failure. Although it did not reach statistical significance, patients with successful aortic valve repair had thinner, more compliant, and more elongated leaflets than did the failure group. Tethering, adhesions, rolled leaflet edge, and the number of involved leaflets were not statistically significant factors in determining success or failure of aortic valve repair.

Aortic valves best suited for repair would seem to be those in which a torn or perforated cusp is discovered in an otherwise normal geometric setting. This type of aortic valve regurgitation is largely acquired rather than developmental. Iatrogenic or traumatic cusp injury may be related to cardiac catheterization, blunt trauma, repair of ventricular septal defect, or mitral valve repair or replacement. ${ }^{13}$ No such injury of an otherwise normal valve was encountered among these children. In this series, leaflet disruption was part of a structurally pathologic valve, and all such valve repairs failed. Unless traumatic or iatrogenic, a torn leaflet likely represents severe intrinsic mechanical stress that may preclude successful repair.

Reduction of cusp prolapse in children with moderate to severe aortic insufficiency associated with ventricular septal defect has produced somewhat more reliable outcomes and should probably always be attempted. Annular reduction by plication techniques remains reasonable in the relatively unusual instance of annular ectasia with normal valve leaflets. Finally, because aortic insufficiency is a risk factor for failure of the Ross procedure, ${ }^{14}$ attempts at primary repair still seem justified in selected instances.

\section{Conclusion}

Among children with congenital aortic valve anomalies who are seen with dominant aortic insufficiency, valve repair should be reserved for those whose leaflets remain thin, compliant, and perhaps redundant. Repair may also be useful among children whose aortic valve pathology is acquired in nature, such as in the presence of a ventricular septal defect. Complex valve pathologies may require more aggressive techniques of repair than used in this series or may be better managed with valve replacement alternatives.

\section{References}

1. Cosgrove DM, Rosenkranz ER, Hendren WG, Bartlett JC, Stewart WJ. Valvuloplasty for aortic insufficiency. J Thorac Cardiovasc Surg. 1991;102:571-7.

2. Duran C, Kumar N, Gometza B, al Halees Z. Indications and limitations of aortic valve reconstruction. Ann Thorac Surg. 1991;52:447-54.

3. Duran CM, Gometza B. Aortic valve reconstruction in the young. J Card Surg. 1994;9(2 Suppl):204-8.

4. DeLeon SY, Quinones JA, Miles RH, Hofstra J, Bell TJ, Fisher EA, et al. Use of the native aortic valve as pulmonary valve in Ross procedure. Ann Thorac Surg. 1995;59:1007-10.

5. Mercer JL, Benedicty M, Bohnson HT. The geometry and construction of the aortic leaflet. J Thorac Cardiovasc Surg. 1973;65:511-8.

6. Silver FC, Roberts WC. Detailed anatomy of the normally functioning aortic valve in hearts of normal and increased weight. Am J Cardiol. $1985 ; 55: 454-61$

7. Kalangos A, Beghetti M, Baldovinos A, Vala D, Bichel T, Mermillod $\mathrm{B}$, et al. Aortic valve repair by cusp extension with the use of fresh autologous pericardium in children with rheumatic aortic insufficiency. J Thorac Cardiovasc Surg. 1999;118:225-36. 
8. Caspi J, Ilbawi MN, Roberson DA, Piccione W, Monson DO, Najafi H. Extended aortic valvuloplasty for recurrent valvular stenosis and regurgitation in children. J Thorac Cardiovasc Surg. 1994;107:111420.

9. Ilbawi MN, DeLeon SY, Wilson WR, Roberson DA, Husayni TS, Quinones JA, et al. Extended aortic valvuloplasty: a new approach for the management of congenital valve aortic stenosis. Ann Thorac Surg. 1991;52:663-8.

10. Al Fagih MR, Al Kasab SM, Ashmeg A. Aortic valve repair using bovine pericardium for cusp extensions. J Thorac Cardiovasc Surg. 1988;96:760-4.

11. Aitizaz-Uddin S, Bhat AN, Bukhari AE, Al Fagih MR. Aortic valve repair in children: to the editor. Ann Thorac Surg. 1997;64:1223.

12. Haydar HS, He GW, Hovaguimian H, McIrvin DM, King DH, Starr A Valve repair for aortic insufficiency: surgical classification and techniques. Eur J Cardiothorac Surg. 1997;11:258-65.

13. Hill AC, Bansal RC, Razzouk AJ, Liu M, Bailey LL, Gundry SR. Echocardiographic recognition of iatrogenic aortic valve leaflet perforation. Ann Thorac Surg. 1997;64:684-9.

14. Laudito A, Brook MM, Suleman S, Bleiweis MS, Thompson LD, Hanley FL, et al. The Ross procedure in children and young adults: a word of caution. J Thorac Cardiovasc Surg. 2001;122:147-53.

\section{Discussion}

Dr Michel N. Ilbawi (Oak Brook, Ill). I enjoyed the article, and I congratulate you on your attempt to analyze aortic valvuloplasty as a method of dealing with aortic valve disease in children. As you know, it is very important, especially since the Ross procedure in pediatric patients has questionable long-term results, that we pay more and more attention to aortic valvuloplasty and its long-term outcome.

I agree with your conclusion that aortic valvuloplasty at present is still a palliative procedure. However, I take issue with the contention that we should limit it to selected cases. I believe that the procedure has a sound concept. Its results can be improved, and as a matter of fact are improving.

The improvements in the results are secondary to our better understanding of the aortic valve pathology. We know now that for aortic valvuloplasty to be successful we have to attack the aortic valve not only at one anatomic variable but at the three variable anatomic parameters: the sinotubular bar, the leaflets (their depth and length), and the aortoventricular junction, the so-called the annulus of the valve.

In your study I could not find anything that relates to any of these parameters. Did you look into the sinotubular bar in these patients? Did you measure that? Did you look into the pathology of the sinotubular bar? Did you measure the diameter of the annulus? If so, what have you done about that? How did you incorporate it into your correction of the valve?

Dr Hasaniya. Thank you, Dr Ilbawi, for your comments. All these comments are valid points, which are the point of discussion by most of the recent articles. Unfortunately, this was a retrospec- tive study, and we really did not look into these parameters. We just took all instances of pure aortic insufficiency; we haven't really looked into these parameters.

Dr Ilbawi. Most of the time the pathology of the valve is not limited to one leaflet, and I could see from your techniques that you have primarily addressed only one variable and one leaflet. Can you give me a better idea of how many leaflets you have managed during the repair? Have you done only one leaflet per valve or two? Have you associated that with any additional measures to secure the leaflets?

Dr Hasaniya. We had few patients with more than one leaflet involved. They also underwent repair. Involvement of more than one leaflet did not predict failure.

Dr Ilbawi. This is also very important: if I look at the failure rate, you had a total of 9 patients out of the 19 patients. And 7 of those 9 patients had valve prolapse after the repair. The leaflets prolapsed after the repair, causing recurrence of the regurgitation. I wonder why you have excluded suspension of these leaflets with the addition of pericardial augmentation to ensure that your leaflets are at the level of the sinotubular bar, have better coaptation, and will not prolapse as readily as they did in your series?

Dr Hasaniya. As I said, cusp augmentation, as you have previously reported, was not one of the techniques used. I might ask Dr Gundry to comment on that.

Dr Steven R. Gundry (Palm Springs, Calif). Just to help my colleague out, Len Bailey and I did the vast majority of these repairs. And we did, where indicated, attack the sinotubular junction by narrowing it and also attacked the annulus by placing subcommissural sutures to narrow the annulus as well as indicated in our article.

What we did not use was full cusp augmentation with pericardium. However, we did augment some of the cusp with pericardium where there was deficiency or an actual perforation. So we tried all these techniques. And I guess the point of this article is that either Len and I aren't very good at this or we're reporting something that other people have seen as well.

Dr Antonio Laudito (Jackson, Miss). Would you share with us your selection process in treating patients with the Ross procedure or with a mechanical aortic prosthesis?

Dr Hasaniya. Usually the decision is tailored to individual patient requirements and is based on several issues, including the age, size, and sex of the patient and the availability of pulmonary homografts. Preoperative choice of the patient and family and the perceived ability of the patient to comply with warfarin sodium anticoagulation are considered. Younger, smaller infants and children and girls are preferentially treated with the Ross operation. Patient or parental choice largely determines the type of procedure among older, larger children and adolescents. 